\title{
NUMERICAL MODELING OF WAVE INTERACTION WITH A NON-CONVENTIONAL BREAKWATER FOR WAVE ENERGY CONVERSION
}

\author{
Enrico Di Lauro, Università degli studi della Campania “Luigi Vanvitelli”, enrico.dilauro@unicampania.it \\ Maria Maza, Environmental Hydraulic Institute "IHCantabria”, Univ. de Cantabria, mariaemilia.maza@unican.es \\ Javier L. Lara, Environmental Hydraulic Institute "IHCantabria", Univ. de Cantabria, jav.lopez@unican.es \\ Inigo J. Losada, Environmental Hydraulic Institute "IHCantabria", Univ. de Cantabria, inigo.losada@unican.es \\ Diego Vicinanza, Università degli studi della Campania “Luigi Vanvitelli”, diego.vicinanza@unicampania.es
}

\section{INTRODUCTION}

The hybrid non-conventional breakwaters are innovative coastal structures, which have as a primary function the coastal and harbours protection, but with the important benefit of electricity production, due to their combination with Wave Energy Converters. The most recent example of a non-conventional breakwater is called OBREC, standing for Overtopping BReakwater for Energy Conversion (Vicinanza et al., 2014). The device consists of a traditional rubble mound breakwater, in which the seaward armour layer in the upper part is replaced with a frontal sloping ramp and a reservoir. The structure is designed to capture and gather the water that overtops the crest ramp (Fig. 1). The potential energy of the water stored in the reservoir is converted into kinetic energy and then into electrical energy by flowing through low head hydraulic turbines coupled with generators, exploiting the different water levels between the reservoir and the sea level.

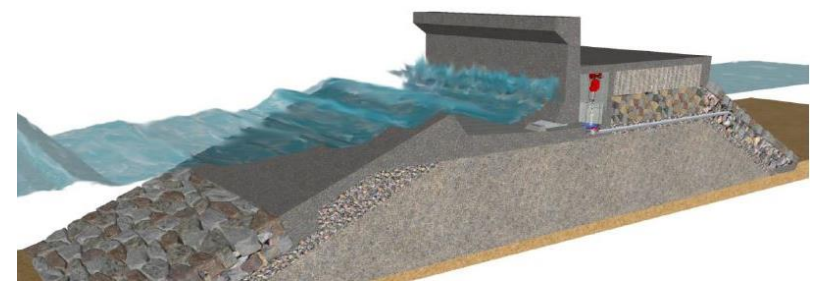

Figure 1 - Conceptual design of the OBREC

\section{NUMERICAL MODEL}

Although the hydraulic performances of the OBREC has been tested in two physical model test campaigns (Vicinanza et al., 2014, Contestabile et al., 2017) and a full scale prototype is currently under monitoring, a numerical analysis is carried out with the aim to attain a deeper understanding of the wave-structure interaction phenomena. In this paper, a two-dimensional numerical model based on the Volume-Averaged ReynoldsAverage Navier-Stokes (VARANS) equations, IH-2VOF (Lara et al., 2011), is used for this purpose. The model has been largely adopted in coastal engineering to evaluate the interaction between waves and traditional breakwaters. Moreover, the model has been used by Palma et al. (2016) for numerical simulation on the OBREC, comparing the results with data from the test campaign carried out in 2012 (Vicinanza et al., 2014). The present paper shows results validated against experimental data from test campaign performed in 2014 and presented by Contestabile et al. (2017). The computational domain is designed to fully replicate the wave flume and the laboratory set-up. Moreover, contrary to previous numerical simulation on the OBREC (Palma et al., 2016), irregular waves were generated using the real movement of the wave maker in the laboratory as inputs, following the virtual boundary force method explained in Lara et al., (2011). Consequently, the numerical results are here validated through a direct time series comparison with the signals measured in the laboratory test.

\section{RESULTS}

The comparison between the laboratory and numerical data shows that the model is able to simulate the waveOBREC interaction, in terms of the water surface elevation in front of the structure, wave reflection and wave loading exerting on the device. Fig. 2 shows an example of the good agreement between the numerical and measured time series of the free surface elevation in front of the OBREC for an irregular test with significant wave height, $\mathrm{H}_{\mathrm{s}}$, of $0.116 \mathrm{~m}$, a peak period, $\mathrm{T}_{\mathrm{p}}$, of $1.484 \mathrm{~s}$ and a water depth, $h$, of $0.35 \mathrm{~cm}$ at the toe of the structure. Please note that the first wave gauge (Gauge 1) is placed at $3.4 \mathrm{~m}$ from the toe of the structure, while the other gauge, closest to the structure, is placed at a distance of $0.30 \mathrm{~m}$ from the Gauge 1.

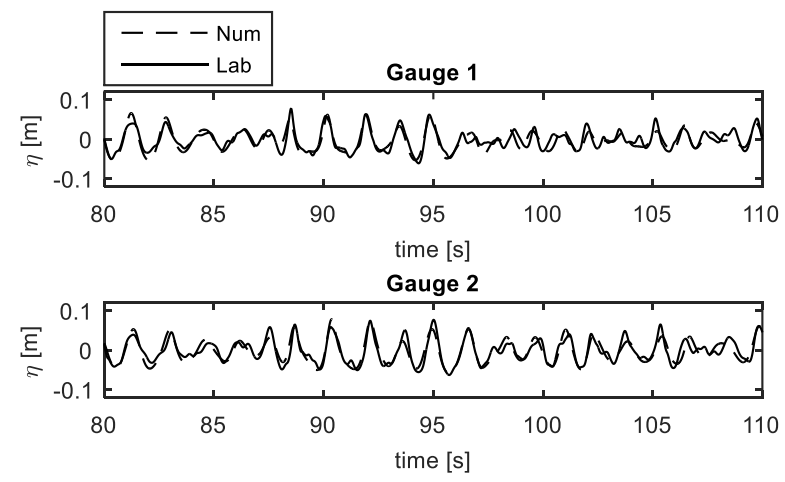

Figure 2 - Free surface elevation for two gauges located in front of the OBREC model (black line: laboratory measurement, black dotted line: numerical computations)

\section{REFERENCES}

Contestabile, luppa, Di Lauro, Cavallaro, Andersen, Vicinanza (2017): Wave loadings acting on innovative rubble mound breakwater for overtopping wave energy conversion, Coastal Engineering, vol. 122, pp. 60-74. Lara, Ruju, Losada (2011): Reynolds averaged NavierStokes modelling of long waves induced by a transient wave group on a beach, Proc. of the Royal Society of London A: Mathematical, Physical and Engineering Sciences, vol. 467, pp. 1215-1242.

Palma, Contestabile, Mizar Formentin, Vicinanza, Zanuttigh (2016): Design optimization of a multifunctional wave energy device, 2nd International Conference of Renewable Energies Offshore, 24-26 October 2016, Lisbon, Portugal, pp. 235-240. Vicinanza, Contestabile, Nørgaard, Lykke-Andersen (2014): Innovative rubble mound breakwaters for overtopping wave energy conversion, Coastal Engineering, vol. 88, pp. 154-170. 